\title{
Surgery for Pericardial Syndromes in Adults and Children: Clarification of Questionable Aspects
}

\author{
Ahmed Abdelrahman Elassal1,2*, Osman Osama Al-Radi', Husain Hamza Jabbad1, \\ Zaher Faisal Zaher ${ }^{3}$, Mohamed Hasan Abdelsalam ${ }^{3,4}$, Ahmed Mohamed Dohain ${ }^{3,5}$, \\ Gaser Abdelmohsen Abdelmohsen ${ }^{3,5}$, Khalid Ebrahim Al-Ebrahim ${ }^{1}$
}

${ }^{1}$ Cardiac Surgery Unit, King Abdulaziz University, Jeddah, Saudi Arabia

${ }^{2}$ Cardiothoracic Surgery Department, Faculty of Medicine, Zagazig University, Zagazig, Egypt

${ }^{3}$ Pediatric Cardiology Division, King Abdulaziz University Hospital, Jeddah, Saudi Arabia

${ }^{4}$ Department of Cardiology, Faculty of Medicine, Benha University, Benha, Egypt

${ }^{5}$ Cardiology Division, Department of Pediatrics, Faculty of Medicine, Cairo University, Cairo, Egypt

Email: *samalassal1434@gmail.com

How to cite this paper: Elassal, A.A., Al-Radi, O.O., Jabbad, H.H., Zaher, Z.F., Abdelsalam, M.H., Dohain, A.M., Abdelmohsen, G.A. and Al-Ebrahim, K.E. (2020) Surgery for Pericardial Syndromes in Adults and Children: Clarification of Questionable Aspects. World Journal of Cardiovascular Surgery, 10, 213-225.

https://doi.org/10.4236/wjcs.2020.1011024

Received: October 6, 2020

Accepted: November 14, 2020

Published: November 17, 2020

Copyright $\odot 2020$ by author(s) and Scientific Research Publishing Inc. This work is licensed under the Creative Commons Attribution International License (CC BY 4.0).

http://creativecommons.org/licenses/by/4.0/ (c) (i) Open Access

\begin{abstract}
Background: The knowledge on pericardial disease has increased but the European Society of Cardiology in the last guidelines 2015 stated a section of perspective and unmet needs referring to the surgical management as one of these needs. Here, we present an institutional experience to contribute with other studies in explanation of questionable aspects about their surgical management. Methods: Among 127 cases (93 adults and 34 children) that were diagnosed as pericardial syndrome, we retrospectively analyzed 45 cases ( 40 adults and 5 children) operated for pericardial syndrome from May 2012 to June 2019. Echocardiogram was the main preoperative diagnostic tool. Surgical approach was selected according to each diagnosis. Postoperative clinical assessment, recurrence and mortality rate were the main determinants of outcome. Results: Regarding pericardial effusions, the mean preoperative medical treatment period was $17.7 \pm 21.9$ days and pericardial window through thoracotomy was the common approach (54.5\%). In constrictive pericarditis, infection was the main etiology $(40 \%)$, mean preoperative medical treatment period was $16 \pm 8.8$ days and complete pericardiectomy was the surgical procedure for most cases. Trans-sternal drainage was the standard approach for cardiac tamponade. No postoperative same admission recurrences were reported and $11(24.4 \%)$ mortalities were recorded, 7 (15.5\%) cases of them were diagnosed as malignant effusions. Conclusion: Decision making and surgical approach affect the outcome of surgery for pericardial syndromes. Children are more responsive to medical treatment than adults are. Primary etiol-
\end{abstract}


ogy and patient's condition are still the leading determinants of morbidity

and mortality.

\section{Keywords}

Surgery, Pericardial Syndromes, Adults, Children

\section{Introduction}

Pericardial syndromes as defined by European Society of Cardiology (ESC) are acute pericarditis, pericardial effusion, constrictive pericarditis and cardiac tamponade. Four years have elapsed since the last international guidelines on the diagnosis and management of the pericardial diseases published by the ESC in 2015 [1]. Additionally, different trials, cohorts and guidelines by Brazilian and Spanish national societies of cardiology have been published in the same issue [2] [3]. Since then, the knowledge on pericardial diseases has increased but the ESC stated a section of perspective and unmet needs referring to the surgical management as one of these needs. Moreover, Spanish society of cardiology mentioned that there are gaps in the ESC guidelines referring to limited relevance of surgical and interventional techniques [4]. Accordingly, we present our experience to contribute with other studies in expanding knowledge about the surgical management of pericardial syndromes aiming to conclude widely accepted decision making for better outcomes.

\section{Methods}

Among 127 cases (93 adults and 34 children) were diagnosed as pericardial syndrome, analytic retrospective study was designed in King Abdulaziz University (KAU) for 45 patients ( 40 adults and 5 children) from May 2012 to June 2019 who were surgically treated for pericardial syndromes among total number of 1857 cases operated for heart disease. The remaining 82 patients (53 adults and 29 children), who were managed by medical treatment or percutaneous intervention, were not analyzed in our study but we obtained their plans of management from recorded data base of adult and pediatric cardiology units. The ethical committee in KAU approved our study and all patients were consented. From stepwise analysis of our study we tried to clarify the following raised questionable aspects: 1) decision making and time of surgery, 2) Initial conservation versus surgery, 3) Choice of surgical approach, 4) Role of surgery in children, 5) Management of chylopericardium. Additionally, incidences of different etiologies of pericardial disease were recorded in our study for more expansion of knowledge.

Workups: Clinical examination, routine labs investigation, chest $\mathrm{X}$ ray and echocardiogram (ECHO) were the basic preoperative diagnostic tools. Microbiological, cytological and biochemical fluid analysis were routinely done for peri- 
cardial effusions. Pericardial tissue culture and histopathology are routine labs investigation after surgery. Preoperative C-reactive protein (CRP) was done for constrictive pericarditis. Computerized tomography (CT) was ordered to confirm diagnosis in selected cases like extent of calcifications in constrictive pericarditis. Right heart catheterization was indicated for constrictive pericarditis when noninvasive tools were not conclusive.

Decision making and time of surgery: Initial surgery was our preferred option for loculated, recurrent or posterior pericardial effusions. In adults, early or even urgent surgery was indicated for post-pericardiotomy effusions due to adhesions and labile hemodynamics after primary surgery. However in children, conservative management was effective in most of the cases. Urgent or even emergent surgery was indicated in cardiac tamponade post cardiac trauma or surgery. In malignant effusions, surgery was our choice for symptomatic patients with more than 6 months life expectancy especially in recurrent cases after palliation and percutaneous pericardial drainage. Regarding rare primary pericardial tumor associated with pericardial effusion, we preferred initial surgery to drain the effusion and to resect tumor in the same setting. In constrictive pericarditis, we recommended to start with medical treatment for non-advanced cases as most etiologies are infective and medical treatment alleviated both symptoms and the pathology especially in children. However in advanced symptoms like intractable heart failure or aggressive pathology like dense fibrosis or calcification, early surgery was rational. In chylopericardium, we decided to do surgery after failure of medical treatment plus percutaneous drainage in primary idiopathic etiology but we did surgery from the start for iatrogenic postoperative chylopericardium.

Surgical approaches: 1) Subxiphoid drainage: Insertion of pericardial tube was performed through small $1.5 \mathrm{~cm}$ subxiphoidal incision while the patient in a semi setting position without endotracheal intubation for severely distressed cases. 2) Trans-sternal drainage: It was indicated for post pericardiotomy effusions after cardiac surgery and for cardiac tamponade post cardiac trauma or surgery. We opened the sternum as a standard case of redo surgery then suctioning and washing of the pericardium with control of bleeder if present. 3) Trans-sternal drainage plus resection of pericardial tumor: It was indicated for pericardial tumor complicated by pericardial effusion for drainage and resection of the tumor in the same setting. 4) Thoracic duct mass ligation: It was performed through median sternotomy for chylopericardium plus bilateral chylothorax post cardiac surgery. Trans-sternal approach enables us to access all fluid cavities. 5) Pericardial window: It was performed for most cases of pericardial effusions especially recurrent cases, malignant effusions and primary idiopathic chylopericadium. Our preferred approach was small left anterolateral thoracotomy then excising a rectangular piece of the lateral surface of pericardium measuring about $3 \mathrm{~cm} \times 5 \mathrm{~cm}$ and above the course of left phrenic nerve. In loculated effusions, we gently did blunt finger dissection anteriorly, posteriorly and laterally around the heart to open loculations and permit free drainage. Lastly we 
inserted left sided pleural tube. In high risk, we used the video-assisted thoracoscopy (VATS) to create the window. 6) Pericardiectomy: We performed all pericardiectomies through the full median sternotomy without cardiopulmonary bypass (CBP) except 2 pediatric cases were on $\mathrm{CPB}$ aiming to do radical pericardiectomy. In all adult cases, complete pericardiectomy was our standard technique. The extent was to resect constrictive pericardium as much as possible from left phrenic nerve to the right except one case we extended resection to the diaphragmatic surface, superior vena cava and inferior vena cava which defined as total pericardiectomy. If calcified pericardium deeply invaded the myocardium, we relieved the pericardium with sharp incisions to release constriction of calcified pericardium, which is called "pericardial meshing" or the "turtle cage technique".

Follow up: Patients were evaluated by postoperative clinical assessment, chest $\mathrm{X}$ ray and $\mathrm{ECHO}$ in the same admission then similarly repeated after two weeks. After one month in the cardiothoracic surgery clinic, if no recurrence or complications, we referred them for more follow up with cardiology clinic. Postoperative clinical assessment, period of postoperative mechanical ventilation, period of intensive care unit stay, period of hospital stay, recurrence and mortality rate were the determinants of outcome.

Data obtained from the medical records were compiled in an Excel spreadsheet and then processed Categorical variables are presented as frequency and percentage. Continuous variables are presented as mean \pm standard deviation.

\section{Results}

The 45 patients, who were surgically treated for pericardial syndrome, were diagnosed as 22 cases of pericardial effusions, 10 cases of constrictive pericarditis and 13 cases of cardiac tamponade. Incidence of operations for pericardial syndromes among other cardiac operations recorded $2.4 \%$. Surgery was indicated for $35.4 \%$ of all patients who were diagnosed as pericardial syndrome. Pericardial effusion was the most common diagnosis (48.8\%) in all cases. Among 93 cases of pericardial syndromes in adults, surgery was indicated for $43 \%$ of them while surgery was performed for only $14.7 \%$ among 34 cases of pericardial syndromes in children. $85.3 \%$ of pediatric cases revealed complete recovery by medical treatment alone or accompanied by percutaneous pericardial intervention (Figure 1). The recorded 5 pediatric cases (11.1\%) presented as constrictive pericarditis in two cases ( 2 years old female and 11 years old male), cardiac tamponade in one case ( 9 years old male) post cardiac trauma, one case (3 months old male) of pericardial Teratoma associated with pericardial effusion, and chylopericardium in one case ( 8 months old male) post cavopulmonary shunt (Glenn shunt).

Pericardial effusions: The most common cause was metastatic adenocarcarcinom (31.8\%) followed by post pericardiotomy syndrome (22.7\%). Infectious etiology by stenotrophomonas maltophilia organism was recorded in one adult 


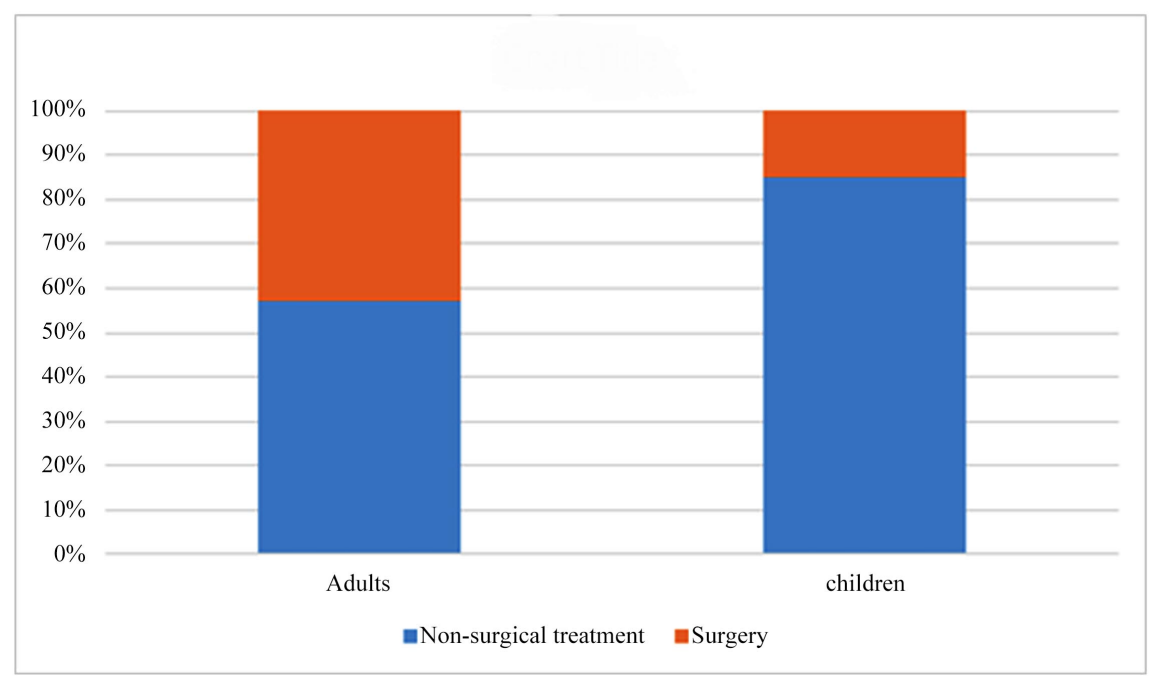

Figure 1. Chart showing the percentage of candidates for surgical versus non-surgical treatment of pericardial syndromes in adults and children, it reveals that non-surgical intervention is more effective in children than adults.

case. Preoperative percutaneous drainage was done for 14 cases (63.6\%) and pericardial window through left anterolateral thoracotomy was the most common surgical approach (54.5\%). Subxiphoid drainage by chest tube insertion was done for a critically ill 53 years old female diagnosed as cancer cervix with massive malignant pericardial effusion. Procedure was performed under local anesthesia in semi sitting position as general anesthesia was difficult due to severe respiratory distress, morbid obesity and short neck. Median sternotomy (transsternal drainage) was indicated for 5 adult cases with post pericardiotomy effusions (one case of Bentall-De Bono operation plus aortic arch replacement, 2 cases of mitral valve replacement and 2 cases of aortic valve replacement), and for 2 pediatric cases ( 3 months old male) diagnosed as pericardial Teratoma associated with pericardial effusion (Figure 2 \& Figure 3 ), and chylopericardium in a 8 months old male post Glenn shunt). Pericardial window with VATS was performed in a 73 years old cachectic male diagnosed as mediastinal Hodgkin's lymphoma with metastatic malignant pericardiopleural effusion. Other demographic, preoperative, surgical and outcome data are shown in Table 1.

Cardiac tamponade: Post cardiac surgery was the most common cause (84.6\%) and all occurred early postoperatively except one adult case post CABG, cardiac tamponade occurred late after 10 days as a result of avulsion of the proximal anastomosis of venous graft during retrieving of retrosternal chest tube drain. The patient was re-explored emergently and he was successfully rescued. Median sternotomy was done for all cases. A 9 years old child was rescued from cardiac tamponade post cardiac trauma by gunshot. The bullet penetrated the wall of right atrium and settled in the posterior mediastinum (Figure 4). The approach was median sternotomy and the case survived. Other demographic, preoperative, surgical and outcome data are shown in Table 2. 


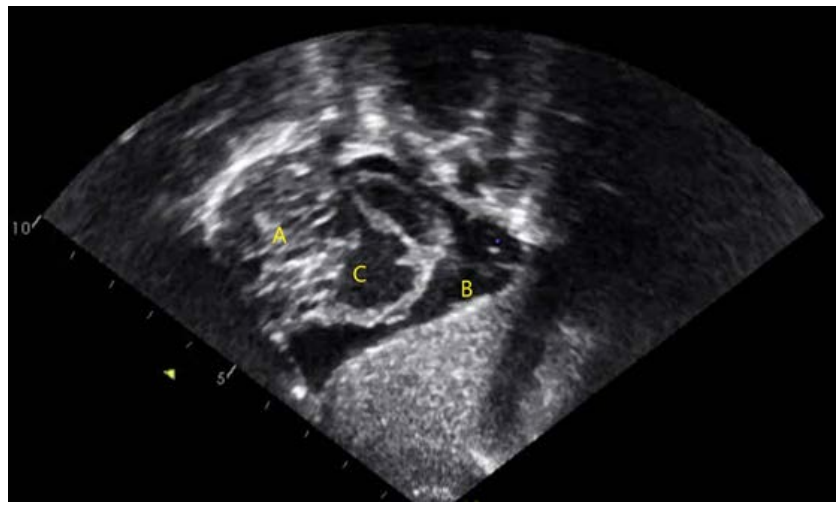

Figure 2. Transthoracic echocardiography of baby with intrapericardial Teratoma associated with pericardial effusion: (A) Teratoma mass. (B) Pericardial effusion. (C) Right atrium.

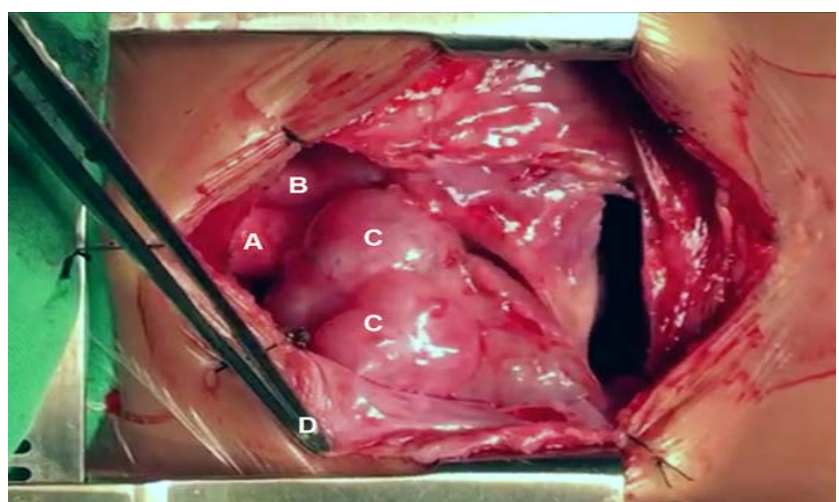

Figure 3. Intaoperative picture showing intrapericardial teratoma (same baby of Figure 2): (A) Ascending aorta. (B) Pulmonary artery. (C) Large lobulated Intrapericardial Teratoma mass adherent to ascending aorta and right atrium. (D) Tip of forceps reflecting the pericardium.

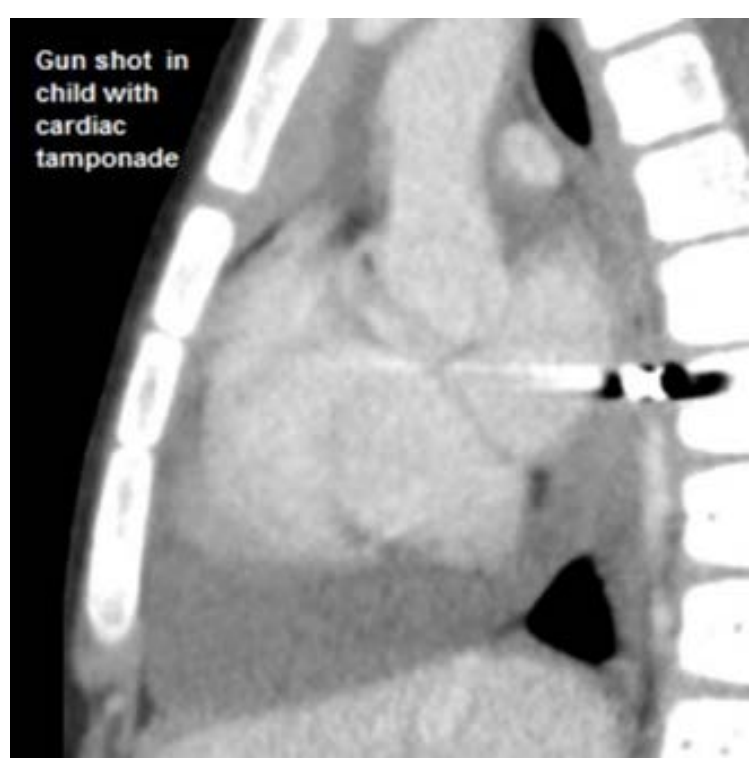

Figure 4. Computerized tomography of the chest showing penetrating gunshot injury with cardiac tamponade in child. 
Table 1. Demographic, preoperative, surgical and outcome data of pericardial effusion.

\begin{tabular}{|c|c|}
\hline \multicolumn{2}{|l|}{ Demographic data: } \\
\hline age & $37.9 \pm 16.8$ years \\
\hline $\operatorname{sex}$ & No. cases (Percentage ) \\
\hline male & $12(54.5 \%)$ \\
\hline female & $10(45.5 \%)$ \\
\hline \multicolumn{2}{|l|}{ Etiology: } \\
\hline - Infectious & 1 case \\
\hline - Neoplastic & $11(50 \%)$ \\
\hline - Traumatic & $7(31.8 \%)$ \\
\hline - Idiopathic & $2(9.2 \%)$ \\
\hline - Metabloic & 1 case \\
\hline \multicolumn{2}{|l|}{ Diagnosis of pericardial disease: } \\
\hline Metastatic adenocarcinoma & $7(31.8 \%)$ \\
\hline Post pericardiotomy syndrome & $5(22.7 \%)$ \\
\hline Transudative pericardial effusion & $2(9.2 \%)$ \\
\hline Chylopericadium & $2(9.2 \%)$ \\
\hline Metastatic Hodgkin iymphoma & 1 case \\
\hline Pericardial Teratoma & 1 case \\
\hline Dressler syndrome & 1 case \\
\hline Pyogenic pericarditis & 1 case \\
\hline Idiopathic pericarditis & 1 case \\
\hline Ureamic pericarditis & 1 case \\
\hline \multicolumn{2}{|l|}{ Onset: } \\
\hline acute & $2(9.2 \%)$ \\
\hline subacute & $17(77.2)$ \\
\hline chronic & $3(13.6)$ \\
\hline \multicolumn{2}{|l|}{ Size: } \\
\hline moderate & $4(18.2 \%)$ \\
\hline large & $18(81.8 \%)$ \\
\hline Symptomatic cases: & $21(95.4 \%)$ \\
\hline Haemodymaic impact: & $14(63.6 \%)$ \\
\hline \multicolumn{2}{|l|}{ Distribuation: } \\
\hline - localized & $8(36.4 \%)$ \\
\hline - circumferncial & $14(63.6 \%)$ \\
\hline \multicolumn{2}{|l|}{ Pre operative management: } \\
\hline - Radiation & $13(59 \%)$ \\
\hline - Chemotherapy & $12(54.5 \%)$ \\
\hline - Associated Pleural effusion & $13(59 \%)$ \\
\hline - Preop period of medical treatment/day & $17.7 \pm 21.9$ \\
\hline - Preop percutaneous drainage & $14(63.6 \%)$ \\
\hline \multicolumn{2}{|l|}{ Surgical data: } \\
\hline \multicolumn{2}{|l|}{ Time of surgery } \\
\hline - Emergent & $2(9.2 \%)$ \\
\hline - Urgent & $13(59 \%)$ \\
\hline - Elective & $7(31.8 \%)$ \\
\hline \multicolumn{2}{|l|}{ Surgical approach } \\
\hline - Subxyphoid & $3(13.6 \%)$ \\
\hline - Left anterolateral thoracotomy & $12(54.5 \%)$ \\
\hline - Sternotomy & $6(27.2 \%)$ \\
\hline - VATS & 1 case \\
\hline \multicolumn{2}{|l|}{ Outcome: } \\
\hline - Period of MV/day & $37.9 \pm 16.8$ days \\
\hline - Period of ICU stay/day & $5.1 \pm 5.6$ days \\
\hline - Period of Hospital stay/day & $23.3 \pm 26.5$ days \\
\hline - Recurrent & 1 case $(4.6 \%)$ \\
\hline - Mortality & 8 cases $(36.4 \%)$ \\
\hline
\end{tabular}

VATS: Video assisted thoracoscopic surgery, MV: Mechanical ventilation, ICU: Intensive care unit. 
Table 2. Demographic, preoperative, surgical and outcome data of cardiac tamponade.

\begin{tabular}{ll}
\hline Demographic data: & \\
Age & $31.8 \pm 21.2$ year \\
Sex & No. cases (Percentage ) \\
Male & $2(15.4 \% \%)$ \\
Female & $11(84.6 \%)$ \\
Etiology: & \\
Post CABG & $4(30.8 \%)$ \\
Post double valve replacement & $2(15.4 \%)$ \\
Post commando operation & 1 case \\
Post Bentall-De Bono operation & 1 case \\
Post ECHO guided pericardial drainage & 1 case \\
Post mitral valve replacement & 1 case \\
Post aortic valve replacement & 1 case \\
Delayed Postop, coronary graft avulsion & 1 case \\
Penetrating cardiac trauma & 1 case \\
Surgical approach: Median sternotomy & All cases \\
Outcome: & \\
- Period of MV/day & $3.5 \pm 3.8$ days \\
- Period of ICU stay/day & $5.3 \pm 3.5$ days \\
- Period of Hospital stay/day & $17.1 \pm 6.3$ days \\
- Mortality & 1 case \\
\hline
\end{tabular}

CABG: Coronary artery bypass grafting, ECHO: Echocardiography, MV: Mechanical ventilation, ICU: Intensive care unit.

Constrictive pericarditis: Infectious cause represented $40 \%$ and mycobacterium tuberculosis (TB) was the causative organism in all cases except one case revealed methicillin-resistant staphylococcus aureus (MRSA) in microbiological panel. The mean preoperative medical treatment period was $16 \pm 8.8$ days. Complete pericardiectomy was done for 6 adult cases, total pericardiectomy for one adult case, radical pericardiectomy for 2 pediatric cases and pericardial meshing (turtle cage technique) for one adult case with severely calcified pericardium (Figure 5). Other demographic, preoperative, surgical and outcome data are shown in Table 3.

Outcomes: The mean period of postoperative hospital stay in pericardial effusions was $23.3 \pm 26.5$ days, in constrictive pericarditis were $18 \pm 10.1$ days and in cardiac tamponade was $17.1 \pm 6.3$ days. Early postoperative recover of symptoms among survivors (34 cases) was recorded in 31 cases (91.1\%). Two adult cases of malignant pericardial effusion revealed persistent dyspnea after surgery due to systemic dissemination of primary malignant tumor especially to the bronchopreural structures. Additionally, adult male patient with calcified pericardium revealed postoperative persistent heart failure because of preoperative low $\mathrm{EF} \%$ $<30 \%$. No recurrence in survivors was reported in early postoperative period or referred later from cardiology clinic. All mortalities were 11 adult cases, 7 of them (63.6\%) presented with malignant etiology. The remaining 4 mortalities were not directly related to surgical procedures and three cases of them died from septic shock. The cause of septic shock in 2 cases was postoperative resistant stenotrophomonas maltophilia and MRSA infections despite prolonged 


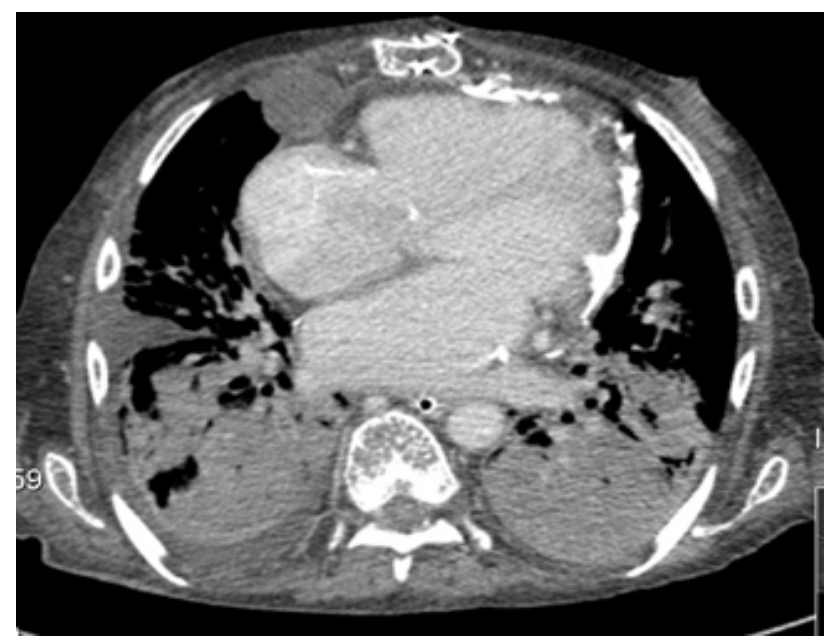

Figure 5. Postoperative computerized tomography of the chest of adult male showing "pericardial meshing" or the "turtle cage technique".

Table 3. Demographic, preoperative, surgical and outcome data of constrictive pericarditis.

\begin{tabular}{ll}
\hline Demographic data: & \\
Age & $31.8 \pm 21.2$ year \\
Sex & No. cases (Percentage) \\
Male & $6(60 \%)$ \\
Female & $4(40 \%)$ \\
Etiology: & \\
- Infectious & $5(50 \%)$ \\
- Autoimmune & $2(20 \%)$ \\
- Idiopathic & $2(20 \%)$ \\
- Metabolic & $1(10 \%)$ \\
Preop period of medical treatment/day & $16 \pm 8.8$ days \\
Surgery: & \\
Complete pericardiectomy & $6(60 \%)$ \\
Total pericardiectomy & $1(10 \%)$ \\
Radical pericardiectomy & $2(20 \%)$ \\
Pericardial meshing & $1(10 \%)$ \\
Outcome: & \\
- Period of MV/day & $3.6 \pm 5.9$ days \\
- Period of ICU stay/day & $5.6 \pm 5.7$ days \\
- Period of Hospital stay/day & $18 \pm 10.1$ days \\
- Mortality & 2 cases $(20 \%)$ \\
\hline
\end{tabular}

MV: Mechanical ventilation, ICU: Intensive care unit.

sensitive antimicrobial regimens, while in the third case, it was as a result of intractable sever chest infection from prolonged mechanical ventilation due to co-morbidities in an immunocompromized cerebral palsy patient. The fourth case was uremic pericarditis and died from end stage renal disease.

\section{Discussion}

Surgery for pericardial syndromes among other cardiac surgery procedures is relatively rare, often surgery is required but still there is controversy regarding standard strategies and techniques [5]. We recorded $2.4 \%$ incidence of opera- 
tions for pericardial syndromes among other cardiac operations. Fardman et al. (2016) stated that children share comparable etiology and diagnostic criteria of pericardial syndromes with adults but the inflammatory process could be more obvious in children [6]. However, it was deduced from our study that surgical indications are limited in children and medical treatment or percutaneous drainage were effective for most cases (85.3\%) but in adults, the indications of surgery $(43 \%)$ versus medical treatment or percutaneous drainage (57\%) were comparative. ECHO becomes the confirmatory study for diagnosis of pericardial disease and it has replaced cardiac catheterization. The last reserved for situations where ECHO is ambiguous [7]. In all our cases, ECHO was the main confirmatory study except one case of constrictive pericarditis with low $\mathrm{EF} \%<30 \%$, we did catheterization to confirm diagnosis as ECHO was not conclusive. Our indications for surgical treatment of pericardial effusions are the same as reported by Langdon et al. (2016). They recommended surgery for patients with good life expectancy despite advanced disease and did not recommend it for less than 6 months of life expectancy. Additionally, they considered one recurrent episode after percutaneous drainage especially indwelling catheter is rational to do surgery [8]. In post cardiac injury syndromes in adults, we agree with Kudaiberdiev (2019) that post cardiac injury effusions mainly need surgery for re-exploration for optimum drainage as they are usually localized and can cause hemodynamic compromise. In children, medical treatment or percutaneous drainage are effective modalities with limited cases that need surgery [9]. Idiopathic primary chylopericardium is extremely rare, Kwon et al. identified one case of lymphatic leak communicating with pericardial sac in 75 years old male defined it as primary idiopathic silent chylopericardium, and they postulated that conservative management failed in $60 \%-70 \%$ of cases so early pericardial window without thoracic duct ligation was their preferred management [10]. We recorded same case presentation of 35 years old female but our management was different. Initially, we treated the patient medically plus indwelling catheter for 10 days but both failed to manage leak, so pericardial widow without thoracic duct ligation was done with good outcome. Therefore, we agree with Kwon et al. (2013) about early surgery without preoperative conservation. Additionally, we preferred just doing pericardial window reserving thoracic duct ligation for recurrence. Regarding secondary iatrogenic etiology, we selected pericardial window with thoracic duct ligation to manage pediatric case with chylopericardium post cavopulmonary shunt. Subxyphoid approach of pericardial window is better than thoracotomy regarding postoperative pain and earlier postoperative extubation. In contrast, the thoracotomy may be more effective at preventing recurrence [8] [11]. In our study, $54.5 \%$ of cases with effusions were approached by small thoracotomy as it enabled us to fashion proper window. The risk of mortality as reported by several publications has noted equivalent perioperative and long-term mortality rates associated with the two window techniques, with survival more dependent on pre-existing conditions rather than on the type of the 
incision employed and a recurrence rate of only 3.2\% [8] [11]. We recorded early 3 mortalities post-surgical drainage not related to the procedure itself but related to compromise pre-existing condition. Majority of deaths were late and among malignant cases. No early or referred recurrent effusions among survivors. VATS is a good less invasive approach especially for compromised patients but it needs well trained team. We did VATS for high risk, compromised and cachectic case diagnosed as mediastinal Hodgkin's lymphoma with metastatic malignant pericardiopleural effusion to create pericardial widow and tissue biopsy. Pericardiectomy is not advised during early presentation of constrictive pericarditis or in severe advanced disease when the risks of surgery-with a mortality rate of $30 \%$ to $40 \%$-outweigh the benefits [12]. Hence, we followed medical treatment in those patients for at least $16 \pm 8.8$ days especially in children and if no improvement we proceeded to pericardiectomy. Constrictive Pericarditis requiring pericardiectomy is very uncommon in children, along 30 years from 1978 to 2008, Thompson et al reported only 16 cases and they did complete pericardiectomy for refractory cases not responding to medical treatment [13]. We reported 2 pediatric cases diagnosed constrictive pericarditis and required radical pericardiectomy. Bertog et al. [14] have defined complete pericardiectomy as the phrenic-to-phrenic resection Chowdhury et al. [15] have defined total pericardiectomy as a wide excision of the pericardium up to the phrenic nerves posteriorly, the great vessels superiorly, and the diaphragmatic surface including the inferior vena cava inferiorly. In addition, McCaughan et al. [16] have described radical pericardiectomy that includes excision of the pericardium posterior to the left phrenic nerve up to pulmonary veins. Despite debate on the exact extent of resection, most of the literatures recommended the complete pericardiectomy which should be enough for relief of symptoms and hemodynamic improvement, which is consistent with our experience [17] [18]. Zhu et al. (2015) reported nine patients among 165 had early postoperative deaths after pericardiectomy due to low cardiac output syndrome. Autopsy findings suggested that myocardial fibrosis and atrophy in these patients [19]. One adult case in our study diagnosed as ureamic pericarditis and died from end stage renal disease.

\section{Conclusion}

More experiences are required to fulfill unmet needs and questionable gaps issued by committees concerned with surgical management of pericardial syndromes. Recurrence and intractability after medical and interventional treatments are still the main primary indications and determinates of surgical options especially in elective situations. Early surgical treatment of post cardiac injury syndromes and chylopericardium may ensure better outcomes. Children are more responsive to medical treatment but surgery should not be delayed in cases of persistent symptoms or relapses. Postoperative mortality and morbidity depend mainly on preoperative etiology of the disease and pre-existing patient 
condition rather than surgical techniques.

\section{Limitations of the Study}

The main limitations of the current study are 1) It is a retrospective one and statistics were analysis of patient variables only to present more data from specialized center. 2) The data originate from different pathologies in diverse populations because we are aiming to present just an institutional experience for surgical management of pericardial diseases in adult and children. A larger number and prospective randomized trials needed to standardize a roadmap for management of pericardial diseases.

\section{Conflicts of Interest}

The authors declare no conflicts of interest regarding the publication of this paper.

\section{References}

[1] Task Force, M., Adler, Y., Charron, P., Imazio, M., Badano, L., Baron-Esquivias, G., et al. (2015) 2015 ESC Guidelines for the Diagnosis and Management of Pericardial Diseases: The Task Force for the Diagnosis and Management of Pericardial Diseases of the European Society of Cardiology (ESC) Endorsed by: The European Association for Cardio-Thoracic Surgery (EACTS). European Heart Journal, 36, 2921-2964. https://doi.org/10.1093/eurheartj/ehv318

[2] Sagrista, S.J., Almenar, B.L., Ángel, F.J., Bardají, R.A., Bosch, G.X., Guindo, S.J., et al. (2000) The Clinical Practice Guidelines of the Sociedad Española de Cardiología on Pericardial Pathology. Revista Española de Cardiología, 53, 394-412. https://doi.org/10.1016/S0300-8932(00)75105-0

[3] Montera, M.W., Mesquita, E.T., Colafranceschi, A.S., Oliveira Jr., A.C., Rabischoffsky, A., Ianni, B.M., et al. (2013) Brazilian Guidelines on Myocarditis and Pericarditis. Arquivos Brasileiros de Cardiologia, 100, 1-36. https://doi.org/10.5935/abc.2013S004

[4] Guindo, J. (2015) Comments on the 2015 ESC Guidelines for the Diagnosis and Management of Pericardial Diseases. A Report by the Spanish Society of Cardiology Guidelines Committee Working Group. Revista Española de Cardiología, 68, 1068 1074. https://doi.org/10.1016/j.recesp.2015.11.002

[5] Johnston, D.R. (2017) Surgical Management of Pericardial Diseases. Progress in Cardiovascular Diseases, 59, 407-416. https://doi.org/10.1016/j.pcad.2017.01.005

[6] Fardman, A., Charron, P., Imazio, M. and Adler, Y. (2016) 2016 European Guidelines on Pericardial Diseases: A Focused Review of Novel Aspects. Current Cardiology Reports, 18, 46. https://doi.org/10.1007/s11886-016-0721-1

[7] Cho, Y.H. and Schaff, H.V. (2013) Surgery for Pericardial Disease. Heart Failure Reviews, 18, 375-387. https://doi.org/10.1007/s10741-012-9338-7

[8] Langdon, S.E., Seery, K. and Kulik, A. (2016) Contemporary Outcomes after Pericardial Window Surgery: Impact of Operative Technique. Journal of Cardiothoracic Surgery, 11, 73. https://doi.org/10.1186/s13019-016-0466-3

[9] Kudaiberdiev, T.Z. (2017) Postpericardiotomy Syndrome and Its Complications: Prevalence, Clinical Significance and Management. Heart-Vessels and Transplantation, 1, 55-56. https://doi.org/10.24969/hvt.2017.10 
[10] Kwon, J.B., Choi, S.Y., Kim, C.K. and Park, C.B. (2013) Primary Idiopathic Silent Chylopericardium. Journal of Cardiothoracic Surgery, 8, 28. https://doi.org/10.1186/1749-8090-8-28

[11] Liberman, M., Labos, C., Sampalis, J.S., Sheiner, N.M. and Mulder, D.S. (2005) Ten-Year Surgical Experience with Nontraumatic Pericardial Effusions: A Comparison between the Subxyphoid and Transthoracic Approaches to Pericardial Window. Archives of Surgery, 140, 191-195. https://doi.org/10.1001/archsurg.140.2.191

[12] Depboylu, B.C., Mootoosamy, P., Vistarini, N., Testuz, A., El-Hamamsy, I. and Cikirikcioglu, M. (2017) Surgical Treatment of Constrictive Pericarditis. Texas Heart Institute Journal, 44, 101-106. https://doi.org/10.14503/THIJ-16-5772

[13] Thompson, J.L., Burkhart, H.M., Dearani, J.A., Cetta, F., Oh, J.K. and Schaff, H. (2009) Pericardiectomy for Pericarditis in the Pediatric Population. The Annals of Thoracic Surgery, 88, 1546-1550. https://doi.org/10.1016/j.athoracsur.2009.08.003

[14] Bertog, S.C., Thambidorai, S.K., Parakh, K., Schoenhagen, P., Ozduran, V., Houghtaling, P.L., et al. (2004) Constrictive Pericarditis: Etiology and Cause-Specific Survival after Pericardiectomy. Journal of the American College of Cardiology, 43, 1445 1452. https://doi.org/10.1016/j.jacc.2003.11.048

[15] Chowdhury, U.K., Subramaniam, G.K., Kumar, A.S., Airan, B., Singh, R., Talwar, S. et al. (2006) Pericardiectomy for Constrictive Pericarditis: A Clinical, Echocardiographic, and Hemodynamic Evaluation of Two Surgical Techniques. The Annals of Thoracic Surgery, 81, 522-529. https://doi.org/10.1016/j.athoracsur.2005.08.009

[16] McCaughan, B.C., Schaff, H.V., Piehler, J.M., Danielson, G.K., Orszulak, T.A., Puga, F.J., et al. (1985) Early and Late Results of Pericardiectomy for Constrictive Pericarditis. The Journal of Thoracic and Cardiovascular Surgery, 89, 340-350.

https://www.ncbi.nlm.nih.gov/pubmed/3974269 https://doi.org/10.1016/S0022-5223(19)38783-5

[17] Schwefer, M., Aschenbach, R., Heidemann, J., Mey, C. and Lapp, H. (2009) Constrictive Pericarditis, Still a Diagnostic Challenge: Comprehensive Review of Clinical Management. European Journal of Cardio-Thoracic Surgery, 36, 502-510. https://doi.org/10.1016/j.ejcts.2009.03.004

[18] Nataf, P., Cacoub, P., Dorent, R., Jault, F., Bors, V., Pavie, A., et al. (1993) Results of Subtotal Pericardiectomy for Constrictive Pericarditis. European Journal of Cardio-Thoracic Surgery, 7, 252-255. https://doi.org/10.1016/1010-7940(93)90213-U

[19] Zhu, P., Mai, M., Wu, R., Lu, C., Fan, R. and Zheng, S. (2015) Pericardiectomy for Constrictive Pericarditis: Single-Center Experience in China. Journal of Cardiothoracic Surgery, 10, 34. https://doi.org/10.1186/s13019-015-0237-6 